\title{
Nature of the Aqueous Hydroxide Ion Probed by X-ray Absorption Spectroscopy
}

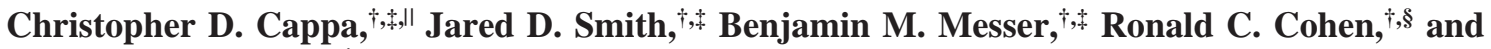 \\ Richard J. Saykally*,,
}

\begin{abstract}
Department of Chemistry, University of California, Berkeley, California 94720-1460, Chemical Sciences Division, Lawrence Berkeley National Laboratory, Berkeley, California 94720, Department of Earth and Planetary Science, University of California, Berkeley, California 94720, NOAA Earth System Research Laboratory, Chemical Sciences Division, Boulder, Colorado 80305
\end{abstract}

Received: January 22, 2007; In Final Form: March 4, 2007

\begin{abstract}
X-ray absorption spectra of aqueous 4 and $6 \mathrm{M}$ potassium hydroxide solutions have been measured near the oxygen $\mathrm{K}$ edge. Upon addition of $\mathrm{KOH}$ to water, a new spectral feature $(532.5 \mathrm{eV})$ emerges at energies well below the liquid water pre-edge feature $(535 \mathrm{eV})$ and is attributed to $\mathrm{OH}^{-}$ions. In addition to spectral changes explicitly due to absorption by solvated $\mathrm{OH}^{-}$ions, calculated XA spectra indicate that first-solvation-shell water molecules exhibit an absorption spectrum that is unique from that of bulk liquid water. It is suggested that this spectral change results primarily from direct electronic perturbation of the unoccupied molecular orbitals of first-shell water molecules and only secondarily from geometric distortion of the local hydrogen bond network within the first hydration shell. Both the experimental and the calculated XA spectra indicate that the nature of the interaction between the $\mathrm{OH}^{-}$ion and the solvating water molecules is fundamentally different than the corresponding interactions of aqueous halide anions with respect to this direct orbital distortion. Analysis of the Mulliken charge populations suggests that the origin of this difference is a disparity in the charge asymmetry between the hydrogen atoms of the solvating water molecules. The charge asymmetry is induced both by electric field effects due to the presence of the anion and by charge transfer from the respective ions. The computational results also indicate that the $\mathrm{OH}^{-}$ion exists with a predominately "hyper-coordinated" solvation shell and that the $\mathrm{OH}^{-}$ion does not readily donate hydrogen bonds to the surrounding water molecules.
\end{abstract}

\section{Introduction}

The nature of the molecular-scale interactions between water molecules and $\mathrm{H}^{+}$and $\mathrm{OH}^{-}$ions is one of the most fundamental issues in modern chemistry. Given that water can spontaneously dissociate into these two ions, it is not surprising that their behavior in liquid water is distinct from that of other ions. For example, the mobility of hydroxide and hydrated protons in liquid water has long been recognized as being anomalously high, ${ }^{1}$ although considerable debate continues as to the underlying causes. ${ }^{2-19} \mathrm{Ab}$ initio molecular dynamics (MD) methods have become particularly useful in the elucidation of the molecular-scale proton and $\mathrm{OH}^{-}$transport mechanisms, which have been shown to depend strongly on both the local solvation environment of the ions and the hydrogen bonding fluctuations of the water molecules. ${ }^{2-8}$ However, despite these important computational advances, disagreement remains with regard to the proper description of $\mathrm{OH}^{-}$mobility in liquid water. ${ }^{6}$

It is therefore important to develop new experiments against which the theoretical results can be tested. To date, neutron diffraction studies of concentrated acid and base solutions have provided important insight into the microscopic structure of aqueous solvated $\mathrm{H}^{+}$and $\mathrm{OH}^{-} .{ }^{10-15}$ Argon vibrational predis-

* To whom correspondence should be addressed. E-mail: saykally@cchem.berkeley.edu.

† Department of Chemistry, University of California, Berkeley.

Chemical Sciences Division, Lawrence Berkeley National Laboratory.

$\S$ Department of Earth and Planetary Science, University of California, Berkeley.

"Present address: NOAA Earth System Research Laboratory, Chemical Sciences Division. sociation spectroscopy of $\mathrm{OH}^{-}\left(\mathrm{H}_{2} \mathrm{O}\right)_{m}$ and $\mathrm{H}^{+}\left(\mathrm{H}_{2} \mathrm{O}\right)_{m}$ clusters has elucidated some aspects of the fundamental ion-water interactions. ${ }^{18,19}$ EUV photoelectron spectroscopy of aqueous $\mathrm{HCl}$ and $\mathrm{NaOH}$ solutions has demonstrated how the solvation environment affects the electron binding energies of the solvated ions and, complementarily, how the presence of the ions influences the water electron binding energies. ${ }^{20}$ Herein, we report the first measurements of the oxygen K-edge X-ray absorption spectrum (XAS) of aqueous potassium hydroxide solutions. The experimental XA spectra are compared to calculated XA spectra and to previously measured XA spectra for other aqueous salt systems, yielding new insights into the nature of the hydroxide ion-water interactions that engender the observed spectral changes. Our results indicate that aqueous hydroxide ions do not readily donate hydrogen bonds to the surrounding water molecules and therefore exist primarily in a hyper-coordinated hydration state.

\section{Methods}

2.1. Experimental. XA spectra of pure water and 4 and $6 \mathrm{M}$ aqueous $\mathrm{KOH}$ solutions were measured on Beamline 8.0.1 at the Advanced Light Source, Berkeley, CA. The experimental design has been described in detail previously. ${ }^{16,21-23}$ Briefly, volatile aqueous solutions are introduced into the high-vacuum environment via a liquid microjet. The total electron yield (TEY) produced from interaction of X-rays with the liquid sample was collected on a copper electrode biased at $+90 \mathrm{~V}$ and located ca. $0.5 \mathrm{~mm}$ from the interaction region. The TEY-XA spectrum provides a measure of the bulk liquid electronic structure, ${ }^{24}$ and, under specified experimental conditions, it is highly reproduc- 
TABLE 1: Basis Sets Used in This Study for Electronic Structure and XA Spectra Calculations ${ }^{a 6,31,34,35}$

\begin{tabular}{|c|c|c|c|c|c|}
\hline \multicolumn{4}{|c|}{ effective core potentials } & \multicolumn{2}{|l|}{ all electron } \\
\hline & orbital & auxiliary & $\mathrm{MCP}^{b}$ & orbital & auxiliary \\
\hline oxygen $^{c}$ & III-IGLO & $(4,3 ; 4,3)$ & & $\operatorname{DZVP}(621 / 41 / 1 *)$ & $(4,3 ; 4,3)$ \\
\hline oxygen & $(+6)(311 / 211 / 1)$ & $(4,3 ; 4,3)$ & $(3,1: 10,0)$ & DZVP $(621 / 41 / 1 *)$ & $(4,3 ; 4,3)$ \\
\hline hydrogen & DZVP2 $\left(41 / 1^{*}\right)$ & $(4,2 ; 4,2)$ & & DZVP2 (41/1*) & $(4,2 ; 4,2)$ \\
\hline chlorine & $(+7)(41 / 31 / 1)$ & $(3,4 ; 3,4)$ & $(4: 6,4)$ & $\operatorname{DZVP}(6321 / 521 / 1 *)$ & $(5,4 ; 5,4)$ \\
\hline bromine & $(+17)(51 / 31 / 41+)$ & $(3,5 ; 3,5)$ & $(3: 7,5)$ & $\operatorname{DZVP}(63321 / 5321 * / 41+)$ & $(5,5 ; 5,5)$ \\
\hline iodine & $(+17)(7 / 5 / 4)$ & $(4,6 ; 4,6)$ & $(5: 12,9,6)$ & $\operatorname{DZVP}(633321 / 53321 / 531 *)$ & $(5,5 ; 5,5)$ \\
\hline
\end{tabular}

${ }^{a}$ Auxiliary basis sets are listed as $\left(n_{\mathrm{c}}(\mathrm{s}), n_{\mathrm{c}}(\mathrm{spd}) ; n_{\mathrm{xc}}(\mathrm{s}), n_{\mathrm{xc}}(\mathrm{spd})\right)$ and indicate the number of $\mathrm{s}$ and spd functions used to fit the coulomb and exchange correlation potentials, respectively. The MCPs are listed as $\left(n_{\mathrm{v}}: n_{\mathrm{s}}, n_{\mathrm{p}}, n_{\mathrm{d}}\right)$, where $n_{\mathrm{v}}$ indicates the number of s-type Gaussians used to fit the potential seen by the valence electrons, and $n_{\mathrm{s}}, n_{\mathrm{p}}, n_{\mathrm{d}}$ are the number of s-, p-, and d-type Gaussians used to describe the core orbitals. The ECP orbital basis sets are listed with their effective charge and are of the form $\left(n_{\mathrm{s}}, n_{\mathrm{p}}, n_{\mathrm{d}}\right)$, where $n_{x}$ is the number of s-, p-, or d-type Gaussians used. ${ }^{b}$ Model core potential. ${ }^{c}$ Core-excited oxygen.

ible. Spectra were measured over the energy range 529-554 $\mathrm{eV}$ at a step size of $0.1 \mathrm{eV}$ and a nominal resolution of $E / \Delta E$ $=5000$. Energy calibration was performed via measurement of the gas-phase water XAS. All of the signals were normalized to the incident photon flux as measured on a gold mesh located $\sim 3 \mathrm{~m}$ upstream of the interaction region. Liquid microjets, controlled by an HPLC pump, are used to introduce the liquid sample (here $T_{\text {liq }} \approx 285 \mathrm{~K}$ ) into the high-vacuum environment, thereby allowing for efficient detection of electrons, convenient temperature control, ${ }^{23,25}$ and rapid renewal of the liquid sample on a microsecond time scale.

2.2. Computational. $X A$ Spectra. All of the calculated XA spectra were generated using the StoBe-DeMon 2.0 program ${ }^{26}$ to calculate oscillator strengths and positions of specific oxygen K-edge transitions. All of the oscillator strengths and energies were calculated from density functional theory (DFT) using a linear combination of Gaussian-type orbitals (LCAO) approach with the transition potential method ${ }^{27}$ under the half core hole approximation. ${ }^{28}$ The BE88 gradient-corrected exchange functional $^{29}$ and the PD86 correlation functional ${ }^{30}$ were used as provided. ${ }^{26}$ The core-excited oxygen is described using the allelectron IGLO-III orbital basis set, ${ }^{31}$ and all of the other oxygen atoms were described using an effective core potential $(\mathrm{ECP})^{32}$ for the valence electrons to facilitate correct identification of the core hole. The calculated transitions were shifted to lower energy by $2.1 \mathrm{eV}$ to obtain agreement between the calculated and experimentally observed water vapor $1 \mathrm{~s} \rightarrow 4 \mathrm{a}_{1}$ transition at $534.1 \mathrm{eV}$.

All of the calculated spectral transitions for water molecules were broadened for presentation using an fwhm of 0.6 below 537.5 and 3 above $540 \mathrm{eV}$ (where these are unshifted energies), with a linear interpolation in between. Because the exact nature of any calculated spectrum depends explicitly on the broadening scheme used, the spectral calculations are used to provide only a qualitative interpretation of the observed XA spectra; a quantitative agreement is not to be expected from this approximate methodology. ${ }^{33}$ However, we note that the use of this broadening scheme yields excellent agreement between the measured and calculated ice XAS. ${ }^{33}$ Additionally, use of this broadening scheme results in reasonable (although not exact) agreement in terms of spectral shape between the experimental pure-water XAS and the average XAS as calculated from a large number of random configurations taken from an SPC/E molecular dynamics simulation. ${ }^{33}$ This can be contrasted with the results obtained using various other schemes (e.g., constant broadening or broadening over a much-larger energy range), which show little resemblance to the experimental XAS. ${ }^{33}$

For $\mathrm{OH}^{-}$ions, a different broadening scheme was used than that described for water molecules because the position of the first calculated spectral transitions and the average ionization potential for the solvated $\mathrm{OH}^{-}$ions are significantly lower than those for water molecules (e.g., the calculated average unshifted IP is $\sim 536.0 \mathrm{eV}$ for solvated $\mathrm{OH}^{-}$and $\sim 539.0 \mathrm{eV}$ for solvated water molecules). Therefore, the $\mathrm{OH}^{-}$spectral transitions were broadened using an fwhm of 0.6 below 534.5 and 3 above 537 $\mathrm{eV}$, with a linear interpolation in between.

Mulliken Charge Populations. Mulliken charge populations, $q$ (atom), have also been calculated for $\left(\mathrm{H}_{2} \mathrm{O}\right)_{2}$ and $\mathrm{X}^{-} \cdot \mathrm{H}_{2} \mathrm{O}$ dimers (where $\mathrm{X}=\mathrm{OH}^{-}, \mathrm{Cl}^{-}, \mathrm{Br}^{-}$, or $\mathrm{I}^{-}$) for both the ground and the core-excited states, using two methodologies. In the first method, the core-excited oxygen is described using the IGLO-III basis set, and the anions and other oxygens are described using ECPs, as we have done previously. ${ }^{21}$ (For the $\mathrm{I}^{-}\left(\mathrm{H}_{2} \mathrm{O}\right)$ cluster, a different basis set was used to describe $\mathrm{I}^{-}$ than in the previous study, ${ }^{21}$ which is the reason the reported Mulliken charges have changed.) In the second method, the anions and all of the oxygen atoms are described using allelectron basis sets, and the half core hole is placed on the oxygen of interest. The basis sets used in this study $26,31,34,35$ are reported in Table 1. This second method likely allows for a better description of the electronic properties of the ground state. However, for the pure-water dimer, the all-electron calculation of the core-excited state yielded unphysical values of the $q$ 's, and therefore, the Mulliken charges are not considered for the excited state. The anion-water dimer geometries were specified such that the $\mathrm{O}-\mathrm{X}^{-}$distances were $3.15\left(\mathrm{Cl}^{-}\right), 3.35\left(\mathrm{Br}^{-}\right), 3.62$ $\left(\mathrm{I}^{-}\right)$, and $2.75 \AA\left(\mathrm{OH}^{-}\right)$, where for $\mathrm{OH}^{-}$the distance is the $R_{\mathrm{OO}}$, and the water molecules were oriented with one hydrogen toward the anion and the other away. Mulliken charges were also calculated for the water molecule with a negative point charge in place of the $\mathrm{OH}^{-}$ion (i.e., with $R_{\mathrm{O}-\mathrm{PC}}=2.75 \AA$ ).

\section{Experimental Results}

The measured K-shell spectra for pure water and for the aqueous $\mathrm{KOH}$ solutions are shown in Figure 1. To facilitate comparison between spectra, all of the spectra have been area normalized over the energy range $529-554 \mathrm{eV}$. The addition of $\mathrm{KOH}$ engenders a strong decrease of the main-edge ( $\sim 538$ $\mathrm{eV})$ peak intensity relative to pure water, where the main-edge peak intensity varied approximately linearly with the $\mathrm{KOH}$ concentration. Linear variation of spectral intensity with addition of salt was previously observed for both the aqueous sodium halide systems ${ }^{22}$ and for aqueous $\mathrm{HCl}^{16}$ The addition of $\mathrm{KOH}$ has a minimal effect on both the pre-edge $(535 \mathrm{eV})$ and the post-edge $(\sim 541 \mathrm{eV})$ intensities, although there is a slight increase in pre-edge intensity and a slight decrease in post-edge intensity. Although only a small change is observed in spectralpeak intensity, the pre-edge structure is significantly broadened compared to pure water such that it no longer exists as a feature 


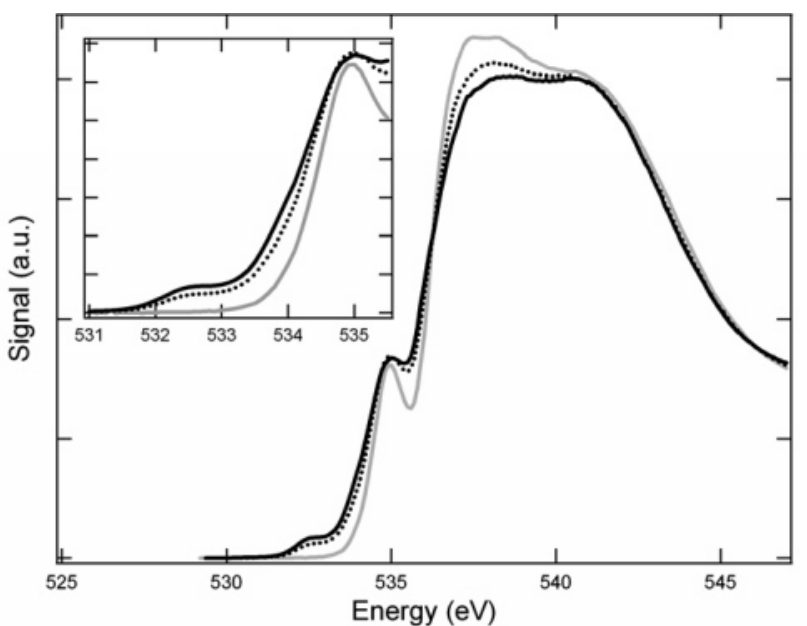

Figure 1. Experimental XAS of pure water (gray) and of aqueous 4 $\mathrm{M} \mathrm{KOH}$ (dotted) and $6 \mathrm{M} \mathrm{KOH}$ (black) solutions. For $\mathrm{KOH}(\mathrm{aq})$ solutions, a new absorption feature is observed prior to the onset of the pure-water absorption. The spectra were area normalized over the energy range $530-554 \mathrm{eV}$. The region of the $\mathrm{OH}^{-}$absorption is shown expanded in the inset figure.

clearly resolved from the main edge. We have previously determined that dissolved monovalent cations have a negligible influence on the XA spectrum of liquid water, ${ }^{16,22}$ and therefore, the observed spectral changes upon $\mathrm{KOH}$ addition result primarily from the presence of the $\mathrm{OH}^{-}$ions.

A new, low-energy feature is observed at $\sim 532.5 \mathrm{eV}$ upon $\mathrm{KOH}$ addition. No such low-energy features have previously been observed upon addition of any sodium halide or monovalent or divalent cation chloride salts, ${ }^{21,22,36}$ or upon $\mathrm{HCl}$ addition. ${ }^{16}$ This suggests that this new feature is a direct probe of the electronic structure of the $\mathrm{OH}^{-}$ion itself and not a result of perturbation of the liquid-water electronic structure by the solvated ions. For comparison, there is some evidence that such low-energy features are also observed upon addition of either $\mathrm{Fe}^{3+}$ or $\mathrm{Cr}^{3+}$ ions but not upon addition of $\mathrm{Al}^{3+} \cdot{ }^{37}$ In that study, the low-energy features were interpreted as arising from orbital mixing between the $d$ shell of the cation and either water molecules or $\mathrm{OH}^{-}$hydroxo complexes, ${ }^{37}$ but it was not considered that the $\mathrm{OH}^{-}$ions might themselves absorb at $E<$ $534 \mathrm{eV}$ without the trivalent cation; clearly, this second possibility must be considered in light of the results presented here. The observation of this low-energy feature is consistent with recent measurement of valence-level electron binding energies of $\mathrm{OH}^{-}$in solution by photoelectron spectroscopy of liquid microjets, which demonstrated that the $\mathrm{OH}^{-}$ionization potential $(9.2 \mathrm{eV})^{20}$ is $2 \mathrm{eV}$ lower than that for liquid water itself $(11.16 \mathrm{eV}) .^{38}$

\section{Discussion}

Our interpretation of the spectral changes observed upon $\mathrm{KOH}$ addition is guided by calculations of XA spectra and by comparison with previously measured XA spectra of various aqueous salt solutions. ${ }^{16,21,22}$ As a starting point, XA spectra of the bare $\mathrm{OH}^{-}$ion and of a free $\mathrm{H}_{2} \mathrm{O}$ molecule have been calculated (Figure 2); the influence of solvation environment will be discussed shortly. These calculations indicate that the bare $\mathrm{OH}^{-}$ion absorbs at lower energies than do free $\mathrm{H}_{2} \mathrm{O}$ molecules, consistent with the experimental observations for the aqueous solutions. The calculated unsolvated $\mathrm{OH}^{-}$spectrum exhibits substantial intensity at $537.9 \mathrm{eV}$, which is in the same energy region as the experimental main edge, and there is

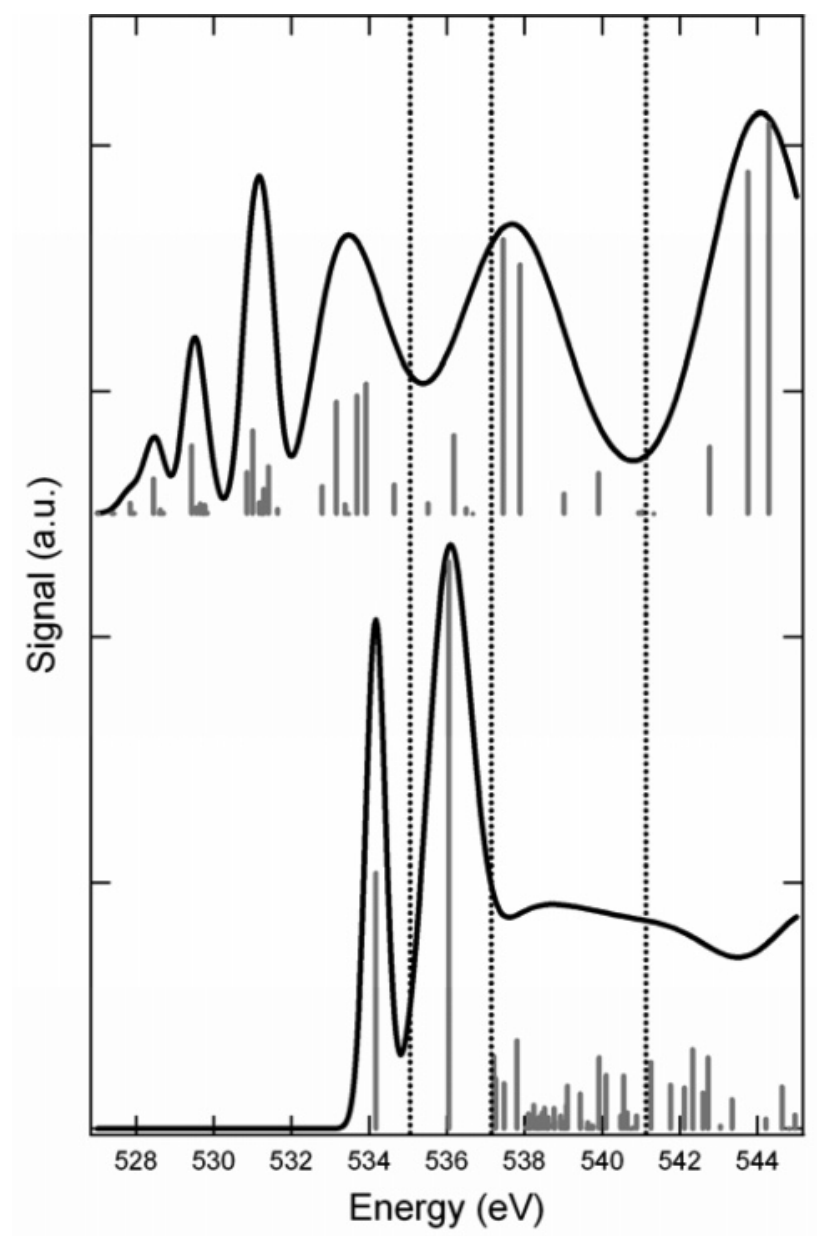

Figure 2. Calculated XAS for a free $\mathrm{H}_{2} \mathrm{O}$ molecule (bottom) and the bare $\mathrm{OH}^{-}$ion (top). The dashed lines indicate the approximate positions of (from left to right) the pre-edge, main edge, and post-edge features in the liquid-water XAS. Note the large intensity appearing at lower energies for the bare ion.

negligible intensity calculated in the post-edge region. Also, for the unsolvated $\mathrm{OH}^{-}$ion, spectral transitions with significant intensity are calculated at energies as low as $528.5 \mathrm{eV}$, well below the lowest experimentally observed feature $(532.5 \mathrm{eV})$.

To assess the influence of hydration on the $\mathrm{OH}^{-}$spectrum, XA spectra have also been calculated for $\mathrm{OH}^{-}$ions solvated by 30 water molecules. Thirty individual molecular configurations were obtained from a molecular dynamics (MD) simulation of $555 \mathrm{SPC} / \mathrm{E}$ water molecules containing a single rigid $\mathrm{OH}^{-}$ ion in a periodic box. ${ }^{20}$ For comparison, calculations of pure bulk liquid water were also performed using 60 randomly selected molecular configurations. (The average spectrum is determined from 37 individual "double-donor" spectra, 21 "single-donor" spectra, and 2 "no-donor" spectra, giving an average of 1.6 donor hydrogen bonds per molecule, as determined using the hydrogen bonding criteria of Wernet et al. ${ }^{39}$ ) From the individual calculations, an average spectrum was determined for both solvated $\mathrm{OH}^{-}$and bulk liquid water (Figure 3 ). The calculated pure-water spectrum, using the configurations from the SPC/E MD simulation, gives very reasonable agreement with the experimental TEY-XA spectrum, particularly given the uncertainty in the choice of the broadening scheme. Note that this conclusion contrasts with that of Nilsson and coworkers, ${ }^{39-41}$ where it is claimed that very poor agreement is found between experimental and calculated average XAS when MD structures are used, although we suspect that the discrepancy is primarily the result of the broadening scheme used by them. ${ }^{33}$ 


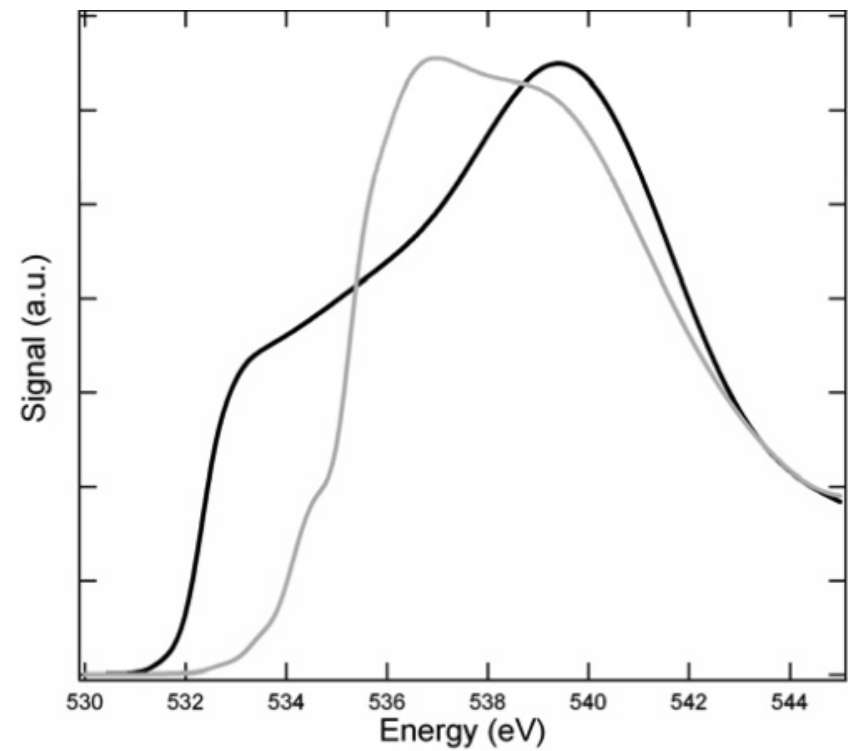

Figure 3. Calculated average liquid-water spectrum (gray) compared to the calculated solvated- $\mathrm{OH}^{-}$spectrum (black).

Nonetheless, comparison between the calculated pure-water XAS and the calculated solvated $\mathrm{OH}^{-}$spectrum reveals that a great deal more intensity is found at lower energies for $\mathrm{OH}^{-}$, with a large "shoulder" peak at $\sim 533 \mathrm{eV}$. This calculated $\mathrm{OH}^{-}$ shoulder-peak can be compared to the calculated pre-edge for pure water at $534.6 \mathrm{eV}$ and the measured new low-energy feature at $532.5 \mathrm{eV}$. Unlike for the bare $\mathrm{OH}^{-}$ion, very little intensity is found below $\sim 532 \mathrm{eV}$, indicating that solvation tends to increase the threshold energy for $\mathrm{OH}^{-}$absorption. We suggest that the generally broad nature of the solvated $\mathrm{OH}^{-}$spectrum is primarily responsible for the observed broadening of the purewater pre-edge upon $\mathrm{KOH}$ addition. The absorption by $\mathrm{OH}^{-}$in the main-edge region is less than that of pure water, which may help to explain the loss of intensity in this region observed upon $\mathrm{KOH}$ addition in the experimental spectrum. Clearly, the salient changes to the pure water XAS upon $\mathrm{KOH}$ addition can be understood to a large extent from the presence of solvated $\mathrm{OH}^{-}$ ions, which exhibit very distinct absorption features from those of bulk $\mathrm{H}_{2} \mathrm{O}$ molecules.

In addition to a direct comparison between the absorption features explicitly due to bulk $\mathrm{H}_{2} \mathrm{O}$ molecules and solvated $\mathrm{OH}^{-}$ ions, it is important to consider the influence of the $\mathrm{OH}^{-}$ion on the electronic structure of the solvating water molecules, either via electric-field effects or charge transfer. Therefore, the average spectra of the first four $\mathrm{OH}^{-}$near-neighbor water molecules, as distinguished by the $\mathrm{O}-\mathrm{O}$ distance, were calculated (Figure 4). The calculated average spectra of these nearestfour $\mathrm{OH}^{-}$neighbor molecules are generally similar. This result is not particularly surprising because, for each of the four $\mathrm{OH}^{-}$ near-neighbor configurations, the vast majority of the $\mathrm{H}_{2} \mathrm{O}$ molecules are oriented with one hydrogen pointed toward the $\mathrm{OH}^{-}$ion, that is, they exist in generally similar molecular environments. Importantly, each of these $\mathrm{OH}^{-}$near-neighbor molecules exhibits strong differences from the calculated purewater spectrum, with a significantly decreased main edge and a slightly increased post-edge. It also appears that the pre-edge feature may be reduced in these $\mathrm{OH}^{-}$neighbor water molecules relative to pure water, but the effect is subtle such that no definitive conclusion can be made. Compared to the calculated solvated $\mathrm{OH}^{-}$spectrum, the spectral intensity in the main-edge and post-edge regions of these first-shell waters is quite similar, but the strong low-energy absorption features found for $\mathrm{OH}^{-}$

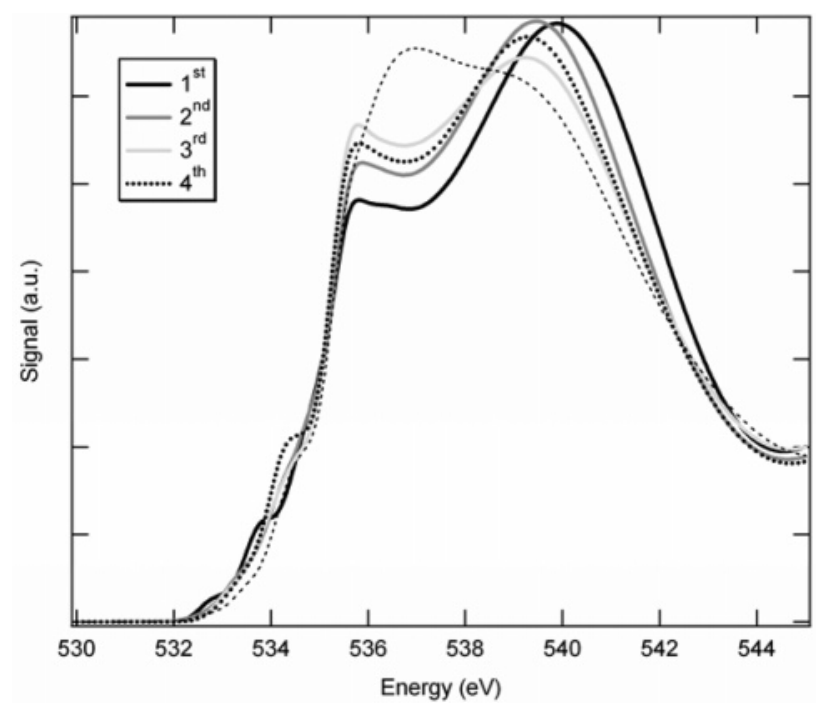

Figure 4. Calculated spectra for the four closest $\mathrm{OH}^{-}$solvation-shell water molecules. Shown for comparison is the calculated bulk-liquid XAS for pure water (dashed line).

are absent. This confirms that the low-energy feature is indeed due to absorption by $\mathrm{OH}^{-}$only. We have also calculated an average spectrum of water molecules far from the $\mathrm{OH}^{-}$ion $(>7$ $\AA$ ), but where the sampled cluster still contains the $\mathrm{OH}^{-}$ion. In this case, the calculated spectrum is effectively identical to the bulk water spectrum.

From these calculations alone, it is not possible to directly and unambiguously establish the origin of the observed changes to the electronic structure of the $\mathrm{OH}^{-}$-solvating water molecules. Specifically, it is difficult to distinguish between the two possibilities: (1) direct perturbation of the electronic structure of the solvating water molecules by the $\mathrm{OH}^{-}$ions and (2) the geometric distortion of the overall hydrogen bond network due to the presence of the ions. Let us consider first the possibility that the calculated differences between the XA spectrum for bulk water molecules and first-shell water molecules are entirely the result of changes to the local hydrogen bond structure. In general, the calculated XA spectrum of the first-shell water molecules more closely resembles an average bulk water doubledonor spectrum than an average single-donor spectrum (not shown), suggesting that perhaps the first-shell water molecules are over-coordinated compared to the bulk. However, from the MD simulation, we can determine hydrogen bond statistics for the solvation-shell water molecules for comparison with the bulk liquid values. It is found that only the first, closest near-neighbor forms more donor HBs than do bulk molecules (1.7 vs 1.6 for the spectra shown in Figures 3 and 4). The next-three closest near-neighbor molecules actually form fewer donor HBs than bulk molecules on average (1.6, 1.4, and 1.4, respectively). Yet, each of the four near-neighbor waters exhibit similar calculated spectra. Thus, it is seems unlikely that geometric distortion of the hydrogen bonding network upon $\mathrm{KOH}$ addition is the primary cause of the observed spectral changes. We therefore suggest, as we asserted previously for dissolved halide anions, ${ }^{22}$ that the spectral changes of the first-solvation-shell water molecules result mainly from distortion of their unoccupied orbitals by the presence of the negatively charged $\mathrm{OH}^{-}$. The nature of this direct electronic perturbation will be discussed further below.

The observed changes to the pure-water XA spectrum engendered by $\mathrm{KOH}$ addition can therefore be understood in terms of the varying degrees of contribution from relatively unperturbed bulk water molecules, strongly perturbed first- 
solvation-shell water molecules, and solvated $\mathrm{OH}^{-}$ions themselves. The $532.5 \mathrm{eV}$ spectral feature in the experimental spectrum arises entirely from absorption by solvated $\mathrm{OH}^{-}$ions. The loss of resolution of the water pre-edge feature likely results from absorption by $\mathrm{OH}^{-}$ions in the region between the preedge and main edge of the water spectrum. The strongly decreased main-edge intensity results from the conversion of some appreciable fraction of the bulk water molecules to $\mathrm{OH}^{-}$solvating water molecules and to the presence of $\mathrm{OH}^{-}$ions, both of which absorb weakly in this region.

The above rationalization of the observed spectral changes assumes that the influence of dissolved $\mathrm{K}^{+}$counterions is negligible. As mentioned above, we have argued previously that the spectral changes observed upon dissolution of monovalent cation-halide salts in water arise primarily from electronic distortion of the unoccupied orbitals of the water molecules solvating the anions ${ }^{22}$ and that the monovalent cations have a negligible effect. ${ }^{16,21}$ This conclusion was reached both by comparison of the observed XA spectra of numerous aqueous monovalent cation chloride solutions (with $\mathrm{Li}^{+}, \mathrm{Na}^{+}, \mathrm{K}^{+}, \mathrm{NH}_{4}{ }^{+}$, and $\mathrm{C}\left(\mathrm{NH}_{2}\right)_{3}{ }^{+}$ions considered), where the observed spectra were independent of the identity of the cation, and by comparison with calculated spectra. The observed spectral changes accompanying the addition of any of these salts to water were very nearly identical despite the very different $R_{\mathrm{OY}}$ distances and solvation structures around the various monovalent cations. ${ }^{21}$ In stark contrast, the addition of $\mathrm{NaX}$ to water (where $\mathrm{X}$ is $\mathrm{Cl}^{-}$, $\mathrm{Br}^{-}$, or $\mathrm{I}^{-}$) engendered strong and distinct, anion-specific changes to the pure-water XA spectrum. ${ }^{22}$ Calculations using small water clusters with a solvated anion or cation supported these observations, with the calculated spectra for ion nearneighbor water molecules in $\mathrm{X}^{-}\left(\mathrm{H}_{2} \mathrm{O}\right)_{x}$ clusters exhibiting a clear dependence on the identity of $\mathrm{X}^{-}$, even when the $R_{\mathrm{OX}}$ distance was constant, ${ }^{22}$ whereas the identity of the cation in $\mathrm{Y}^{+}\left(\mathrm{H}_{2} \mathrm{O}\right)_{x}$ clusters was of negligible importance. ${ }^{16,21}$ In fact, the calculated XA spectrum for double-donor $\mathrm{Na}^{+}$near-neighbor water molecules in 17 molecules clusters was nearly identical to that of double-donor bulk water molecules. ${ }^{16}$

Despite these salient differences in the respective influence of monovalent cations and anions on the water electronic structure from both an experimental and a theoretical standpoint, Nilsson and co-workers have argued that any direct electronic (i.e., "charge-induced"17) perturbation of the solvating water molecules should be the same for anions as for cations because "both ions are singly charged and should polarize the environment to a significant effect." 17 However, such an argument does not consider the fact that first-shell water molecules solvating the anions tend to orient with one hydrogen directed toward the anion, whereas those that solvate cations orient with both hydrogens pointed away from the cation. ${ }^{42}$ Given such a dramatic difference, the influence of anions or cations on the unoccupied orbitals of the solvation-shell water molecules should, in fact, be very different.

Furthermore, Nilsson and co-workers have claimed that the only influence of the chloride anion is to create a longer "hydrogen bond" between the water molecule and the $\mathrm{Cl}^{-}$ion, thus effectively converting some fraction of double-donor water molecules to single-donor molecules and engendering changes to the XA spectrum ${ }^{17}$ (although we note that they had previously "exclude[d] $\mathrm{Cl}^{-}$as a source for the observed changes in the XA spectra" 36 ). This conclusion was based on comparison between calculated XA spectra for pure water, with $R_{\mathrm{OO}}=3.15$ $\AA$, to water with $\mathrm{Cl}^{-}$ions, with $R_{\mathrm{OCl}}=3.15 \AA$, where it was apparently found that the two give "near-identical" spectra

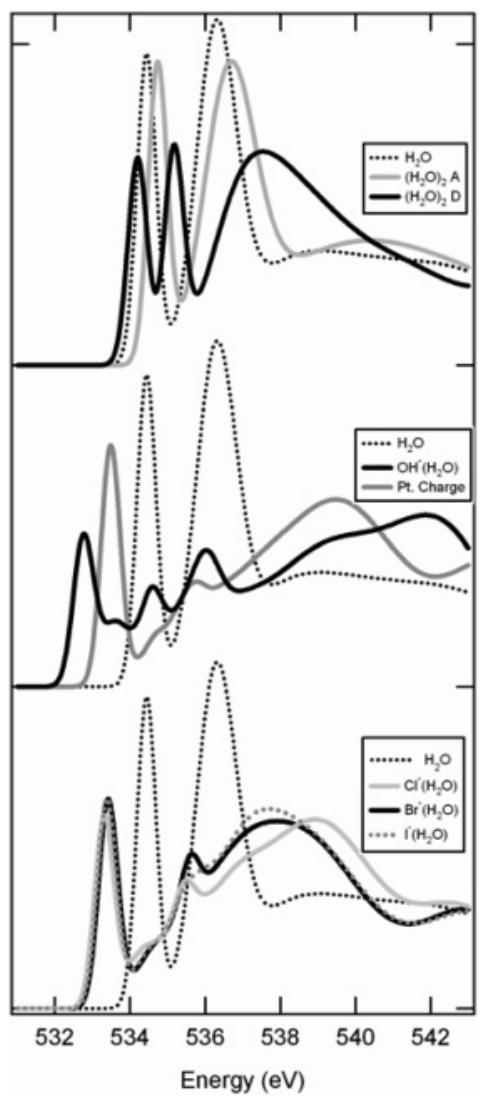

Figure 5. Calculated XA spectra for (top) the donor and acceptor molecules in $\left(\mathrm{H}_{2} \mathrm{O}\right)_{2}$, (middle) the water molecule in the $\mathrm{OH}^{-}\left(\mathrm{H}_{2} \mathrm{O}\right)$ dimer and the water molecule with a point charge in place of $\mathrm{OH}^{-}$, and (bottom) the halide $-\mathrm{X}^{-}\left(\mathrm{H}_{2} \mathrm{O}\right)$ dimers. The calculated $\mathrm{H}_{2} \mathrm{O}$ monomer XAS is shown for comparison.

(although no such spectra were explicitly shown). First, we find that this is actually not the case and that the replacement of a hydrogen bond acceptor water with a $\mathrm{Cl}^{-}$ion leads to a very clear change in the calculated spectra and that the calculated differences depend explicitly on the specified $R_{\mathrm{OO}}$ or $R_{\mathrm{OCl}}$ distance (Figure S1). ${ }^{43}$ Additionally, we have previously shown that if such an analysis is extended to also consider $\mathrm{Br}^{-}$or $\mathrm{I}^{-}$ (still with the condition that $R_{\mathrm{OO}}=R_{\mathrm{OX}}$ ), clear, ion-specific differences between the calculated spectra for pure water and the solvation-shell water molecules are found (cf. Figure 5 of ref 22). Furthermore, as demonstrated above, it is apparent that the first-solvation-shell water molecules around $\mathrm{OH}^{-}$have calculated XA spectra that dramatically differ from that of pure water, despite the generally similar hydrogen bonding environment of the bulk and hydration-shell water molecules with respect to the number of hydrogen bonds formed. Clearly, dissolved anions affect the local electronic structure of the firstshell water molecules in a manner that cannot be adequately described by geometric distortion alone. As such, any interpretation of the observed changes to the experimental water XA spectrum from salt, base, or acid addition strictly in terms of hydrogen bond breaking and forming is incorrect.

It is also interesting to compare the calculated XA spectrum of first-hydration-shell waters of $\mathrm{OH}^{-}$(shown in Figure 4) to that of first-shell waters of the $\mathrm{Cl}^{-}, \mathrm{Br}^{-}$, and $\mathrm{I}^{-}$ions (shown in Figure 4 of ref 22). (Note that the calculations in ref 22 utilized 17 molecule clusters, whereas those here use 30 molecule clusters, which may influence the comparison to some extent but still allow for reasonable qualitative comparison. ${ }^{33}$ ) In the case of the halide anion shell, the calculated main-edge intensity of solvation-shell waters is actually enhanced, whereas for the 
$\mathrm{OH}^{-}$shell it is decreased, compared to that of pure water. This is consistent with the experimental observation that for sodium halide addition the main-edge intensity increases but for $\mathrm{KOH}$ addition it decreases, although part of the decreased main-edge intensity for $\mathrm{KOH}$ addition can be attributed to the particular features of the $\mathrm{OH}^{-}$absorption spectrum (Figure 3). Thus, the halide ions have a qualitatively different effect on the electronic structure of the solvating water molecules than do the $\mathrm{OH}^{-}$ions. This result is generally consistent with results from argon predissociation spectroscopy of $\mathrm{X}^{-}\left(\mathrm{H}_{2} \mathrm{O}\right)$ clusters (where $\mathrm{X}^{-}=$ $\mathrm{OH}^{-}, \mathrm{Cl}^{-}, \mathrm{Br}^{-}$, or $\mathrm{I}^{-}$), where it was found that the vibrational spectrum of $\mathrm{OH}^{-}\left(\mathrm{H}_{2} \mathrm{O}\right)$ clusters ${ }^{19}$ was quite distinct from those of the halide anion clusters. ${ }^{44,45}$ Additionally, the topology of the, for example, $\mathrm{X}^{-}\left(\mathrm{H}_{2} \mathrm{O}\right)_{3}$ clusters is such that for the halide anions (not including $\mathrm{F}^{-}$), inter-water hydrogen bonds are formed between the solvating waters, but for $\mathrm{OH}^{-}$, each of the solvating waters retains a "free" $-\mathrm{OH}$, thereby demonstrating the unique effect of the respective anions on the surrounding water molecules.

It will be demonstrated below that the differing influence of halide versus hydroxide ions on the water XA spectrum likely results from the manner in which the respective anions affect the charge distribution within the first-shell water molecules. This charge redistribution is determined both by electric field effects (i.e., the presence of a negatively charged ion near the water molecules) and by charge transfer between the anion and the solvation-shell waters. Recall that water molecules solvate anions asymmetrically (with one hydrogen pointing toward and one away from the anion), and therefore the two $\mathrm{OH}$ bonds of the solvation-shell waters will likely exist with quite different local electronic environments. Also, charge transfer is known to play an important role in determining the $\mathrm{OH}$ vibrational stretching spectrum of small $\mathrm{X}^{-}\left(\mathrm{H}_{2} \mathrm{O}\right)_{n}$ clusters ${ }^{19,45}$ and has been identified as contributing to the observed XA spectral differences between monovalent and divalent cations. ${ }^{21}$

To better understand the influence of the ions on the electronic structure of the solvating water molecules, we have calculated the Mulliken charge populations for the $\mathrm{X}^{-}\left(\mathrm{H}_{2} \mathrm{O}\right)$ dimers, the pure-water dimer, and for a water molecule with a point charge in place of the $\mathrm{OH}^{-}$ion for both the ground and core-excited states using either all-electron or ECP basis sets (Table 1). Considering first the ground state, analysis of the all-electron $q\left(\mathrm{X}^{-}\right)$indicates that the halide anions redistribute $\sim 6-9 \%$ of their charge to the water molecule, whereas $13 \%$ of the hydroxide ion charge is redistributed to the water molecule. Similar results have been found when the Löwdin charge populations, as determined from ab initio calculations, were instead considered. ${ }^{46,47}$ (Note that when the ECP is used to describe the iodide anion, $q\left(\mathrm{X}^{-}\right)$differs significantly from that calculated for chloride or bromide, whereas, when the allelectron basis set is used, $q\left(\mathrm{X}^{-}\right)$on $\mathrm{Cl}^{-}, \mathrm{Br}^{-}$, and $\mathrm{I}^{-}$are very similar, consistent with ab initio calculations. ${ }^{46}$ Therefore, for the calculations of the ground state $q$ 's we will focus primarily on the results from the all-electron calculations.) For these ground-state ion-water dimers, a notable asymmetry between the $q(\mathrm{H})$ 's of the two water-molecule hydrogens $(q(\Delta \mathrm{H}))$ is found, wherein the hydrogen located between the oxygen and the halide anion is more positive than the free hydrogen, consistent with Löwdin charge populations from previous ab initio calculations. ${ }^{48}$ For the all-electron halide ion-water dimers, $q(\Delta \mathrm{H})$ varies from 0.035 to 0.046 , whereas for the $\mathrm{OH}^{-}\left(\mathrm{H}_{2} \mathrm{O}\right)$ dimer the asymmetry between the hydrogens is significantly larger (0.077). A similar conclusion is found for the ECP $q(\Delta \mathrm{H})$ values.
The all-electron $q$ 's for the $\mathrm{X}^{-}\left(\mathrm{H}_{2} \mathrm{O}\right)$ ground-state dimers can be compared to those for both the donor and the acceptor molecules in $\left(\mathrm{H}_{2} \mathrm{O}\right)_{2}$ and to the $\mathrm{H}_{2} \mathrm{O}$ molecule. The all-electron and ECP $q(\mathrm{O})$ 's for the anion-water dimers are more negative than for either the water molecule or for the donor or acceptor molecules of the pure-water dimer. Also, $q(\Delta \mathrm{H})$ is small for the water-dimer donor molecule and zero for the water-monomer and the water-dimer acceptor. Taken together with the finding that there is a significant difference in $q(\Delta \mathrm{H})$ between $\mathrm{OH}^{-}$ and the larger halide ions, this suggests that hydrogen charge asymmetry on the ground-state solvation-shell water molecules may be particularly important in determining the observed changes in the XA spectrum. Although differences in $q\left(\mathrm{X}^{-}\right)$ between $\mathrm{OH}^{-}$and the halide anions in small water clusters have been previously noted ${ }^{46,47}$ and a hydrogen charge asymmetry for the $\mathrm{I}^{-}\left(\mathrm{H}_{2} \mathrm{O}\right)$ dimer has been identified, ${ }^{48}$ to our knowledge the importance of $q(\Delta \mathrm{H})$ in determining the differing halide versus hydroxide ion behavior in water has not yet been clearly established. It could well be important in explaining the high mobility of aqueous hydroxide.

Because electronic reorganization of the unoccupied orbitals takes place on the time scale of the excitation, it is also important to consider the electronic properties of the core-excited state, from which the calculated XA spectra are obtained. The calculations indicate that $q(\Delta \mathrm{H})$ for both the halide- and hydroxide-ion-water dimers decreases by $\sim 0.1$ in going from the ground to the core-excited state. As such, the difference in $q(\Delta \mathrm{H})$ between the halide- and hydroxide-ion-water dimers observed in the ground state persists in the core-excited state. This suggests that perhaps the primary difference between how $\mathrm{OH}^{-}$and the halide ions affect the first-shell water XA spectrum is established by the ground-state charge distribution and only secondarily by the core-hole relaxation. The change in $q(\Delta \mathrm{H})$ in going from the ground to the core-excited state for the purewater-dimer hydrogen bond donor molecule is smaller than the change found for the anion-water dimers. Thus, there is a difference in the electronic reorganization upon core excitation of the anion-perturbed water molecules (for both the $\mathrm{OH}^{-}$and the halide ions), as compared to pure water.

These differences in the Mulliken charge populations must be understood in the context of how they actually influence the XA spectrum of the water molecule, that is, what are the spectroscopic consequences of the ion-specific variability in the induced water-molecule charge distribution? First, and as has previously been noted, ${ }^{49}$ for the pure-water dimer the acceptormolecule XAS is essentially unchanged from that of isolated $\mathrm{H}_{2} \mathrm{O}$, whereas the donor-molecule XAS is changed significantly, indicating the importance of the formation of donor, as opposed to acceptor, hydrogen bonds (Figure 5, top). This difference has been primarily discussed in terms of localization of the molecular orbitals along the $-\mathrm{OH}$ bonds because of the asymmetric hydrogen bonding configuration of the donor water molecule. In comparison, the halide-water dimers have XA spectra that are distinct from both that of pure $\mathrm{H}_{2} \mathrm{O}$ and from that of the donor $\mathrm{H}_{2} \mathrm{O}$ from $\left(\mathrm{H}_{2} \mathrm{O}\right)_{2}$, although the calculated XASs for the $\mathrm{Cl}^{-}-, \mathrm{Br}^{-}-$, and $\mathrm{I}^{-}-$water dimers are all very similar in the low-energy region and show only small differences at higher energies (Figure 5, bottom). This is consistent with the experimental observation that although the influence of dissolved $\mathrm{NaX}$ on the liquid water XA spectrum is anion specific the associated spectral changes, as compared to pure water, are generally similar in nature. ${ }^{22}$ However, the calculated XA spectrum of the water molecule in the hydroxide-water dimer is distinctly different than the XA spectra of the halide-water 
TABLE 2: Mulliken Charge Populations Calculated for the $\mathrm{X}^{-}\left(\mathrm{H}_{2} \mathrm{O}\right)$ Dimers, $\mathrm{H}_{2} \mathrm{O},\left(\mathrm{H}_{2} \mathrm{O}\right)_{2}$, and $\mathrm{H}_{2} \mathrm{O}$ with a Point Charge in Place of $\mathrm{OH}^{-a}$

\begin{tabular}{|c|c|c|c|c|c|}
\hline & $q\left(\mathrm{X}^{-}(\mathrm{O} / \mathrm{H})\right)$ & $q(\mathrm{O})$ & $q(\mathrm{H} 1)^{b}$ & $q(\mathrm{H} 2)^{c}$ & $q(\mathrm{H} 1-\mathrm{H} 2)$ \\
\hline \multicolumn{2}{|c|}{ Effective Core Potentials } & \multicolumn{4}{|c|}{ Ground State } \\
\hline $\mathrm{OH}^{-}$ & $\begin{array}{l}-0.865 \\
(-1.007 / 0.142)\end{array}$ & -0.586 & 0.242 & 0.209 & 0.033 \\
\hline $\mathrm{Cl}^{-}$ & -0.85 & -0.551 & 0.176 & 0.224 & -0.048 \\
\hline $\mathrm{Br}^{-}$ & -0.869 & -0.54 & 0.18 & 0.228 & -0.048 \\
\hline $\mathrm{I}^{-}$ & -0.802 & -0.557 & 0.143 & 0.216 & -0.073 \\
\hline $\mathrm{H}_{2} \mathrm{O}(\mathrm{D} / \mathrm{A})^{c}$ & & $-0.543 /-0.549$ & $0.254 / 0.289$ & $0.260 / 0.289$ & $0.006 / 0.0$ \\
\hline $\mathrm{H}_{2} \mathrm{O}(\mathrm{A} / \mathrm{D})^{e}$ & & $-0.561 / 0.564$ & $0.284 / 0.295$ & $0.284 / 0.262$ & $0.0 / 0.033$ \\
\hline $\mathrm{H}_{2} \mathrm{O}$ & & -0.545 & 0.272 & 0.272 & 0 \\
\hline \multirow[t]{2}{*}{ pt. charge } & & -0.678 & 0.45 & 0.228 & 0.222 \\
\hline & & \multicolumn{4}{|c|}{ Core-Excited State } \\
\hline $\mathrm{OH}^{-}$ & $\begin{array}{l}-0.784 \\
(-0.966 / 0.182)\end{array}$ & -0.278 & 0.244 & 0.317 & -0.073 \\
\hline $\mathrm{Cl}^{-}$ & -0.752 & -0.24 & 0.157 & 0.335 & -0.178 \\
\hline $\mathrm{Br}^{-}$ & -0.756 & -0.227 & 0.15 & 0.333 & -0.183 \\
\hline $\mathrm{I}^{-}$ & -0.677 & -0.227 & 0.093 & 0.31 & -0.217 \\
\hline $\mathrm{H}_{2} \mathrm{O}(\mathrm{D} / \mathrm{A})^{c}$ & & $-0.275 / 0.556$ & $0.319 / 0.311$ & $0.372 / 0.311$ & $-0.053 / 0.0$ \\
\hline $\mathrm{H}_{2} \mathrm{O}(\mathrm{A} / \mathrm{D})^{e}$ & & $-0.288 / 0.533$ & $0.390 / 0.261$ & $0.390 / 0.279$ & $0.0 /-0.018$ \\
\hline $\mathrm{H}_{2} \mathrm{O}$ & & -0.272 & 0.386 & 0.386 & 0 \\
\hline pt. charge & & -0.362 & 0.505 & 0.357 & 0.148 \\
\hline \multicolumn{2}{|c|}{ All-Electron Basis Sets } & \multicolumn{4}{|c|}{ Ground State } \\
\hline $\mathrm{OH}^{-}$ & $\begin{array}{l}-0.866 \\
(-1.039 / 0.173)\end{array}$ & -0.683 & 0.313 & 0.236 & 0.077 \\
\hline $\mathrm{Cl}^{-}$ & -0.911 & -0.653 & 0.304 & 0.26 & 0.044 \\
\hline $\mathrm{Br}^{-}$ & -0.929 & -0.647 & 0.311 & 0.265 & 0.046 \\
\hline $\mathrm{I}^{-}$ & -0.941 & -0.636 & 0.306 & 0.271 & 0.035 \\
\hline $\mathrm{H}_{2} \mathrm{O}(\mathrm{D})$ & & -0.627 & 0.316 & 0.285 & 0.031 \\
\hline $\mathrm{H}_{2} \mathrm{O}(\mathrm{A})$ & & -0.595 & 0.31 & 0.31 & 0 \\
\hline $\mathrm{H}_{2} \mathrm{O}$ & & -0.596 & 0.298 & 0.298 & 0 \\
\hline \multirow[t]{2}{*}{ pt. charge } & & -0.703 & 0.441 & 0.262 & 0.179 \\
\hline & & \multicolumn{4}{|c|}{ Core-Excited State } \\
\hline $\mathrm{OH}^{-}$ & $\begin{array}{l}-0.776 \\
(-0.999 / 0.214)\end{array}$ & -0.461 & 0.367 & 0.379 & -0.012 \\
\hline $\mathrm{Cl}^{-}$ & -0.812 & -0.439 & 0.342 & 0.409 & -0.067 \\
\hline $\mathrm{Br}^{-}$ & -0.827 & -0.436 & 0.351 & 0.412 & -0.061 \\
\hline $\mathrm{I}^{-}$ & -0.835 & -0.428 & 0.348 & 0.415 & -0.067 \\
\hline \multicolumn{6}{|l|}{$\mathrm{H}_{2} \mathrm{O}(\mathrm{D})$} \\
\hline $\begin{array}{l}\mathrm{H}_{2} \mathrm{U}(\mathrm{A}) \\
\mathrm{H}_{2} \mathrm{O}\end{array}$ & & -0.395 & 0.447 & 0.447 & 0 \\
\hline pt. charge & & -0.473 & 0.551 & 0.423 & 0.128 \\
\hline
\end{tabular}

${ }^{a}$ Calculations were performed using either effective core potentials (top) or all-electron basis sets (bottom) to describe the atoms in both the ground and core-excited states. ${ }^{b} \mathrm{O}-\mathrm{H}-\mathrm{X}^{-}$hydrogen. ${ }^{c}$ Free $\mathrm{OH}$ hydrogen. ${ }^{d}$ Values for the core hole and/or IGLO-III basis set on the Donor. ${ }^{e}$ Values for the core hole and/or IGLO-III basis set on the Acceptor.

dimers, of pure $\mathrm{H}_{2} \mathrm{O}$ and of $\left(\mathrm{H}_{2} \mathrm{O}\right)_{2}$. For example, the first calculated $\left(1 \mathrm{~s} \rightarrow 4 \mathrm{a}_{1}\right)$ transition for the water molecule in the hydroxide-water dimer is located $\sim 0.65 \mathrm{eV}$ below that for the halide-water dimers (Figure 5, middle). Thus, it appears that the variations in the charge distribution among the various anion-water dimers may have real spectroscopic consequences.

The calculations described above provide a physical reasoning for the observed differing influence of the halide and hydroxide ions on the liquid water XAS, that is, there is an anion-dependent hydrogen charge asymmetry induced on the first-solvation-shell water molecules. However, the respective roles of charge transfer and the electric field on the establishment of this asymmetry have not yet been clearly elucidated. To assess the role of the electric field, we have calculated the XA spectrum and $q(\Delta \mathrm{H})$ for a "point-charge dimer," wherein a point charge with $q=-1$ is used in place of the hydroxide ion. In this case, the presence of the point charge engenders a significant hydrogen charge asymmetry in both the ground and the coreexcited states, thereby indicating the importance of the electric field on determining $q(\Delta \mathrm{H})$. However, the magnitude of the calculated charge asymmetry for these point charge dimers is considerably more positive than that of the anion-water dimers (see Table 2). The presence of a point charge also affects the calculated XA spectrum of the dimer (Figure 5). These calculations indicate that the presence of a negative charge near one of the hydrogen atoms (the electric field effect) establishes an initial charge asymmetry but that charge transfer from the ions determines the exact magnitude of $q(\Delta \mathrm{H})$. This in turn suggests that both charge transfer and electric field effects are important in determining the observed XA spectral variations.

One limitation of the above analysis is that the conclusions are based on example calculations using dimers and not fully solvated ions. To explore whether the above conclusions can be generalized to bulk-liquid aqueous systems, we have also calculated the ECP Mulliken populations of core-excited solventshell water molecules using the configurations taken from MD snapshots (Table 3). Compared to the dimers, the calculated average $q\left(\mathrm{X}^{-}\right)$is somewhat less negative for both the $\mathrm{OH}^{-}$and the halide ions, indicating that a greater amount of charge has been transferred to the surrounding water molecules from the anions, although not necessarily exclusively to the core-excited molecule. Overall, the amount of charge transferred from the ion to the solvation-shell waters in the bulk is slightly greater for the halide ions than for the hydroxide ion (i.e., $\mid q$ (halide) $\mid<$ 
TABLE 3: Mulliken Charge Populations Calculated for Core-Excited Water Molecules in the First Solvation Shell of $\mathrm{X}^{-}$ Anions and in Pure Water for Larger Clusters ${ }^{a}$

\begin{tabular}{|c|c|c|c|c|c|}
\hline & $q\left(\mathrm{X}^{-}\right)$ & $q(\mathrm{O})$ & $q(\mathrm{H} 1)$ & $q(\mathrm{H} 2)$ & $q(\mathrm{H} 1-\mathrm{H} 2)$ \\
\hline $\mathrm{OH}^{-}$ & $-0.623(0.027)$ & $-0.364(0.031)$ & $0.259(0.033)$ & $0.326(0.023)$ & $-0.066(0.047)$ \\
\hline $\mathrm{Cl}^{-}$ & $-0.579(0.04)$ & $-0.317(0.026)$ & $0.187(0.054)$ & $0.296(0.048)$ & $-0.109(0.076)$ \\
\hline $\mathrm{Br}^{-}$ & $-0.576(0.063)$ & $-0.301(0.032)$ & $0.175(0.045)$ & $0.318(0.032)$ & $-0.144(0.059)$ \\
\hline $\mathrm{H}_{2} \mathrm{O}$ & - & $-0.337(0.016)$ & $0.324(0.026)$ & $0.350(0.038)$ & $-0.027(0.043)$ \\
\hline
\end{tabular}

${ }^{a}$ Values in parentheses are the $1 \sigma$ standard deviations of the calculated values.

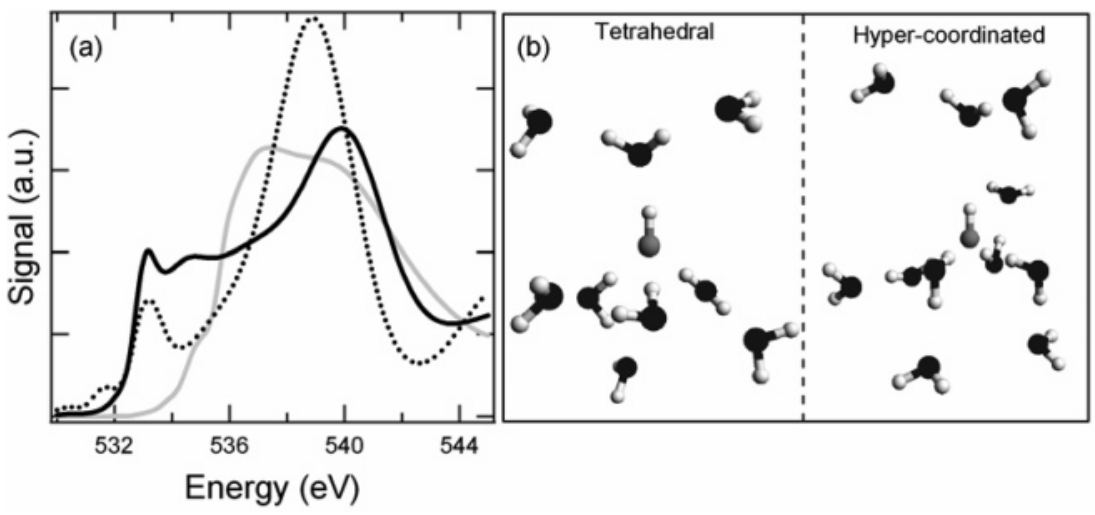

Figure 6. (a) Calculated spectrum for $\mathrm{OH}^{-}$solvated in a tetrahedral environment (dotted black line) and in a hyper-coordinated square-planar environment (solid black line). The calculated bulk water spectrum is shown for comparison (gray line). (b) Depiction of the tetrahedral and hyper-coordinated hydroxide-water clusters used to calculate the spectra shown in panel a.

$\left.\left|q\left(\mathrm{OH}^{-}\right)\right|\right)$, similar to the dimer ECP results. Previous ab initio calculations of $q\left(\mathrm{X}^{-}\right)$for small water clusters indicated that for the halide ions, $q\left(\mathrm{X}^{-}\right)$decreases when the number of solvationshell waters is increased, ${ }^{46}$ whereas $q\left(\mathrm{OH}^{-}\right)$was nearly constant. ${ }^{47}$ With respect to the hydrogen charge asymmetry, the calculated $q(\Delta \mathrm{H})$ 's for the solvated halide ions are more negative than for the solvated hydroxide ions, consistent with the dimer calculations. These bulk calculations therefore also demonstrate the importance of charge transfer in determination of the aqueous-solution XA spectrum.

One other finding of interest is that a slight hydrogen charge asymmetry is also found, on average, for the water molecules in the pure liquid-water simulation. Although $q(\Delta \mathrm{H})$ is close to zero for most configurations, the hydrogen that is involved in a shorter (and therefore stronger) HB is, on average, less positive than the hydrogen that makes a longer HB. This is consistent with the pure-water dimer calculations, where $q(\mathrm{H})$ for the hydrogen involved in the $\mathrm{HB}$ is less positive than for the unbonded hydrogen. This suggests that for pure liquid water the XA spectrum of a given molecule will be determined in part by the instantaneous charge distribution of that molecule as induced by the local geometric environment. Importantly, we note that because these results are derived from configurations obtained from classical MD simulations, the calculated charge asymmetry is a consequence, and not a cause, of the local arrangement of molecules in the simulation.

There currently exists a vigorous debate as to the dominant solvation structure of $\mathrm{OH}^{-}$, namely, whether it accepts hydrogen bonds from three or four water molecules. ${ }^{2-7,13-15}$ The nature of this primary solvation structure has important implications for understanding the transport mechanism of $\mathrm{OH}^{-}$in water and how the mechanism may or may not relate to excess proton $\left(\mathrm{H}_{3} \mathrm{O}^{+}\right)$migration. In principle, the acceptor-bond threecoordinate (tetrahedral) versus four-coordinate (hyper-coordinated) $\mathrm{OH}^{-}$ions should have spectroscopically distinct signatures as a result of the differing local environment thereby allowing for identification of the dominant complex, if one exists.
XA spectra were calculated for $\mathrm{OH}^{-}$in both tetrahedral and hyper-coordinated environments using model 10-molecule or 12-molecule clusters, respectively (Figure 6). In addition to the differing number of hydrogen bonds accepted by the $\mathrm{OH}^{-}$ (where $R_{\mathrm{OO}}=2.6 \AA$ for both tetrahedral and hyper-coordinated structures), the distance between the $\mathrm{OH}^{-}$and hydrogen bond acceptor water also differs between the tetrahedral and hypercoordinated clusters. For the tetrahedral cluster, we use $R_{\mathrm{OO}}=$ $2.6 \AA$ for the distance between $\mathrm{OH}^{-}$and the $\mathrm{H}_{2} \mathrm{O}$ hydrogen bond acceptor molecule, whereas for the hyper-coordinated environment we use a much longer $R_{\mathrm{OO}}$ of $4.0 \AA$. These distances were chosen to be generally consistent with suggestions from MD simulations. ${ }^{20,50}$

The XA spectra for both the tetrahedral and the hypercoordinated $\mathrm{OH}^{-}$model clusters exhibit strong absorption around $532.5 \mathrm{eV}$, the energy where the new spectral feature was experimentally observed. The absorption by the hypercoordinated $\mathrm{OH}^{-}$in this region is somewhat greater than that by the tetrahedral $\mathrm{OH}^{-}$. At higher energies, the calculated spectra for the $\mathrm{OH}^{-}$in the two coordination environments are substantially different. The tetrahedral $\mathrm{OH}^{-}$absorbs strongly (compared to pure water) at $539 \mathrm{eV}$ in a relatively narrow region between the liquid-water XA spectrum main edge and postedge. The hyper-coordinated $\mathrm{OH}^{-}$has a comparably weak absorption in the main-edge region and absorbs only slightly more strongly than water molecules in the post-edge region. Given the changes to the water XA spectrum observed upon $\mathrm{KOH}$ addition (cf. Figure 1), these calculations appear to be more consistent with $\mathrm{OH}^{-}$ions predominately in a hypercoordinated environment.

XA spectra were also calculated for $\mathrm{OH}^{-}$ions in a tetrahedral environment (with respect to the accepted hydrogen bonds) but with $R_{\mathrm{OO}}=4.0 \AA$ for the $\mathrm{OH}^{-}$donor hydrogen bond and for hyper-coordinated $\mathrm{OH}^{-}$ions with $R_{\mathrm{OO}}=2.6 \AA$ for the $\mathrm{OH}^{-}$donor hydrogen bond. It is found that the tetrahedral and hypercoordinated spectra are actually quite similar when the $\mathrm{OH}^{-}-$ $\mathrm{H}_{2} \mathrm{O}$ acceptor distance is the same, that is, the differences between the tetrahedral and hyper-coordinated $\mathrm{OH}^{-}$spectra arise 


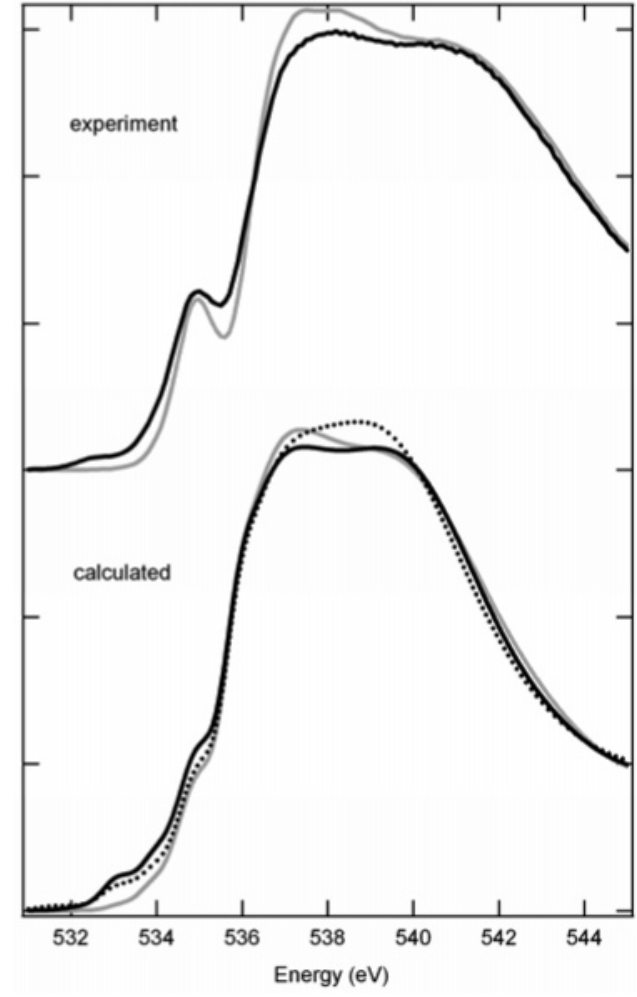

Figure 7. Calculated total spectrum for $\mathrm{OH}^{-}(\mathrm{aq})$ with $\mathrm{OH}^{-}$in either a hyper-coordinated (solid black line) or tetrahedral (dashed line) environment is shown along with the calculated pure-water spectrum (gray line). The differences in the calculated total spectra from pure water can be compared to the observed difference between the XAS for pure water (gray) and $4 \mathrm{M} \mathrm{KOH}(\mathrm{aq})$ (black).

primarily from differences in the $\mathrm{OH}^{-}$donor bond and not from differences in the number of accepted hydrogen bonds. However, MD simulations suggest that the nature of the solvation environment around the $\mathrm{OH}^{-}$hydrogen depends on the $\mathrm{OH}^{-}-$ oxygen solvation environment, that is, an $\mathrm{OH}^{-}$in a tetrahedral (hyper-coordinated) environment (with respect to the hydrogen bond donor water molecules) is generally inconsistent with a excessively long (short) $\mathrm{OH}^{-}-\mathrm{H}_{2} \mathrm{O}$ acceptor $R_{\mathrm{OO}}$ distance on average. ${ }^{50}$ In other words, hyper-coordinated $\mathrm{OH}^{-}$does not readily form donor hydrogen bonds, whereas tetrahedral $\mathrm{OH}^{-}$ does. Therefore, the spectra presented in Figure 6 can be considered as representative of XA spectra for $\mathrm{OH}^{-}$ions in these two different solvation environments.

Of course, any conclusion as to the nature of the $\mathrm{OH}^{-}$ solvation environment based on comparison between the observed and calculated XA spectra must also take into consideration the contribution from $\mathrm{OH}^{-}$solvation-shell water molecules, which the above calculations suggest have an XA spectrum significantly different from that of pure water. Therefore, total spectra have been determined for tetrahedral and hyper-coordinated $\mathrm{OH}^{-}$solutions by summing the spectra for bulk water $(\mathrm{BW}), \mathrm{OH}^{-}$solvation-shell water molecules $(\mathrm{SW})$, and $\mathrm{OH}^{-}$ions $(\mathrm{OH})$ in the different environments and weighting each by its approximate abundance (Figure 7). To approximate a $4 \mathrm{M}$ solution, we use for tetrahedral $\mathrm{OH}^{-}$, total $=0.7 \mathrm{BW}+0.2 \mathrm{SW}+0.1 \mathrm{OH}$; and for hyper-coordinated $\mathrm{OH}^{-}$, total $=0.6 \mathrm{BW}+0.3 \mathrm{SW}+0.1 \mathrm{OH}$. The differences in the $\mathrm{BW}$ and SW terms between tetrahedral and hyper-coordinated solvation reflect the differing number of water molecules that solvate the $\mathrm{OH}^{-}$ions in the different environments. Comparing the calculated total spectra to the observed $4 \mathrm{M} \mathrm{KOH}(\mathrm{aq})$ spectrum, the hyper-coordinated total spectrum is more similar to the observed spectrum than is the tetrahedral total spectrum, again suggesting that $\mathrm{OH}^{-}$in water exists in a predominately hyper-coordinated state (or at least does not readily donate a hydrogen bond to the surrounding water molecules except perhaps transiently). This is consistent with results from both MD simulations ${ }^{7,50}$ and neutron diffraction studies. ${ }^{10,15}$ However, we note that such a conclusion is only suggestive and not definitive given the uncertainties inherent in the calculations, namely, the unavoidably arbitrary nature of the applied broadening scheme and limited success in reproducing the pure liquidwater spectrum in the pre-edge region.

\section{Conclusions}

$\mathrm{X}$-ray absorption spectra at the oxygen $\mathrm{K}$ edge have been measured for aqueous $\mathrm{KOH}$ solutions at 4 and $6 \mathrm{M}$ concentrations. The major spectral changes observed, relative to pure water, result from absorption directly by the solvated $\mathrm{OH}^{-}$ion and by first-hydration-shell water molecules, both of which are shown to have XA spectra that are distinctly different from that of pure liquid water. Compared to pure water, a prominent new low-energy feature was observed at $532.5 \mathrm{eV}$, attributed to absorption by the solvated $\mathrm{OH}^{-}$ion alone. This conclusion was reached by comparison of the calculated solvated $\mathrm{OH}^{-}$spectrum to that of bulk $\mathrm{H}_{2} \mathrm{O}$ and first-hydration-shell water, as well as by comparison to previously measured XA spectra of aqueous sodium halide, monovalent cation chloride, and $\mathrm{HCl}$ solution spectra, for which no such low-energy feature was observed.

These results also indicate that the changes to the electronic structure of the $\mathrm{OH}^{-}$first-hydration-shell water molecules about the hydroxide ion result primarily from direct electronic perturbations of the unoccupied orbitals by the negatively charged $\mathrm{OH}^{-}$ion and only secondarily from geometric distortion of the hydrogen bond network (i.e., the breaking or making of hydrogen bonds). Furthermore, the experimental and computational results both suggest that the nature of the interaction between solvated halide anions and water is fundamentally different than that between solvated $\mathrm{OH}^{-}$and water, given the clearly different effects of the respective anions on the XA spectra. It is suggested that the difference arises primarily from variations in the degree of charge transfer between the ions and the solvation-shell water molecules and from the differing $R_{\mathrm{OX}}$, which determines the strength of the local electric field experienced by the water molecules. In particular, how these properties affect the establishment of a charge asymmetry between the hydrogen atoms of the solvation-shell water molecules is of key importance. Comparison between experiment and calculations also suggests that $\mathrm{OH}^{-}$ions exist in a hyper-coordinated solvation state (with respect to the number of hydrogen bonds accepted by the $\mathrm{OH}^{-}$ion), although unambiguous identification is not possible at this time. Theoretical advances facilitating a truly rigorous comparison of experimental and theoretical XA spectra are urgently needed to help resolve such issues.

Acknowledgment. This research was supported by the Chemical Sciences, Geosciences and Biosciences Division, Office of Basic Energy Sciences, U.S. Department of Energy (RJS) and by the National Science Foundation Atmospheric Chemistry Program under grant no. ATM-0138669 (RCC). The Advanced Light Source is supported by the Director, Office of Science, Office of Basic Energy Sciences, Materials Sciences Division, of the U.S. Department of Energy under contract no. DE-AC03-76SF00098 at Lawrence Berkeley National Laboratory. C.D.C. was supported by the ALS Doctoral Fellowship in 
Residence and the National Defense Science and Engineering Graduate Fellowship. We thank the Advanced Light Source staff, especially Kevin Wilson, Mary Gilles, Bruce Rude, Tolek Tyliczszak, and David Shuh for their support. We thank Prof. Steve Bradforth for providing the hydroxide MD simulations.

Supporting Information Available: Textual description of calculated and XA spectra for water and water-chloride clusters and figures of XA spectra and molecular structures. This material is available free of charge via the Internet at http://pubs.acs.org.

\section{References and Notes}

(1) Bernal, J. D.; Fowler, R. H. J. Chem. Phys. 1933, 1, 515.

(2) Asthagiri, D.; Pratt, L. R.; Kress, J. D.; Gomez, M. A. Chem. Phys. Lett. 2003, 380, 530 .

(3) Asthagiri, D.; Pratt, L. R.; Kress, J. D.; Gomez, M. A. Proc. Nat. Acad. Sci. U.S.A. 2004, 101, 7229.

(4) Chen, B.; Ivanov, I.; Park, J. M.; Parrinello, M.; Klein, M. L. J. Phys. Chem. B 2002, 106, 12006.

(5) Chen, B.; Park, J. M.; Ivanov, I.; Tabacchi, G.; Klein, M. L.; Parrinello, M. J. Am. Chem. Soc. 2002, 124, 8534.

(6) Tuckerman, M. E.; Chandra, A.; Marx, D. Acc. Chem. Res. 2006 39,151 .

(7) Tuckerman, M. E.; Marx, D.; Parrinello, M. Nature 2002, 417, 925.

(8) Marx, D.; Tuckerman, M. E.; Hutter, J.; Parrinello, M. Nature 1999, 397, 601 .

(9) Agmon, N. Chem. Phys. Lett. 2000, 319, 247.

(10) Botti, A.; Bruni, F.; Imberti, S.; Ricci, M. A.; Soper, A. K. J. Chem. Phys. 2003, 119, 5001.

(11) Botti, A.; Bruni, F.; Imberti, S.; Ricci, M. A.; Soper, A. K. J. Mol. Liq. 2005, 117, 77.

(12) Bruni, F.; Ricci, M. A.; Soper, A. K. J. Chem. Phys. 2001, 114, 8056.

(13) Botti, A.; Bruni, F.; Imberti, S.; Ricci, M. A.; Soper, A. K. J. Chem. Phys. 2004, 120, 10154.

(14) Botti, A.; Bruni, F.; Imberti, S.; Ricci, M. A.; Soper, A. K. J. Mol. Liq. 2005, 117, 81 .

(15) Imberti, S.; Botti, A.; Bruni, F.; Cappa, G.; Ricci, M. A.; Soper, A. K. J. Chem. Phys. 2005, 122 .

(16) Cappa, C. D.; Smith, J. D.; Messer, B. M.; Cohen, R. C.; Saykally,

R. J. J. Phys. Chem. B 2006, 110, 1166.

(17) Cavalleri, M.; Naslund, L. A.; Edwards, D. C.; Wernet, P.; Ogasawara, H.; Myneni, S.; Ojamae, L.; Odelius, M.; Nilsson, A.; Pettersson, L. G. M. J. Chem. Phys. 2006, 124.

(18) Headrick, J. M.; Diken, E. G.; Walters, R. S.; Hammer, N. I.; Christie, R. A.; Cui, J.; Myshakin, E. M.; Duncan, M. A.; Johnson, M. A.; Jordan, K. D. Science 2005, 308, 1765.

(19) Robertson, W. H.; Diken, E. G.; Price, E. A.; Shin, J. W.; Johnson, M. A. Science 2003, 299, 1367.

(20) Winter, B.; Faubel, M.; Hertel, I. V.; Pettenkofer, C.; Bradforth, S. E.; Jagoda-Cwiklik, B.; Cwiklik, L.; Jungwirth, P. J. Am. Chem. Soc. 2006, $128,3864$.

(21) Cappa, C. D.; Smith, J. D.; Messer, B. M.; Cohen, R. C.; Saykally, R. J. J. Phys. Chem. B 2006, 110, 5301.

(22) Cappa, C. D.; Smith, J. D.; Wilson, K. R.; Messer, B. M.; Gilles, M. K.; Cohen, R. C.; Saykally, R. J. J. Phys. Chem. B 2005, 109, 7046.
(23) Wilson, K. R.; Rude, B. S.; Smith, J.; Cappa, C.; Co, D. T.; Schaller, R. D.; Larsson, M.; Catalano, T.; Saykally, R. J. Rev. Sci. Instrum. 2004, 75,725 .

(24) Smith, J. D.; Cappa, C. D.; Messer, B. M.; Cohen, R. C.; Saykally, R. J. Science 2005, 308.

(25) Smith, J. D.; Cappa, C. D.; Wilson, K. R.; Messer, B. M.; Cohen, R. C.; Saykally, R. J. Science 2004, 306, 851.

(26) Hermann, K.; Pettersson, L. G. M.; Casida, M. E.; Daul, C.; Goursot, A.; Koester, A.; Proynov, E.; St-Amant, A.; Salahub, D. R. Carravetta, V.; Duarte, H.; Godbout, N.; Guan, J.; Jamorski, C.; Leboeuf, M.; Malkin, V.; Malkina, O.; Nyberg, M.; Pedocchi, L.; Sim, F.; Triguero, L.; Vela, A. StoBe Software, version 2.0; 2004, available at http://w3.rz-berlin.mpg.de/ hermann/StoBe/.

(27) Triguero, L.; Pettersson, L. G. M.; Agren, H. Phys. Rev. B 1998, $58,8097$.

(28) Stöhr, J. NEXAFS Spectroscopy; Springer-Verlag: Berlin, 1992.

(29) Becke, A. D. Phys. Rev. A 1988, 38, 3098.

(30) Perdew, J. P. Phys. Rev. B 1986, 33, 8822.

(31) Kutzelnigg, W.; Fleischer, U.; Schindler, M. The IGLO-Method: $A b$ Initio Calculation and Interpretation of NMR Chemical Shifts and Magnetic Susceptibilities; Springer-Verlag: Heidelberg, 1990, Vol. 23.

(32) Pettersson, L. G. M.; Wahlgren, U.; Gropen, O. J. Chem. Phys. 1987, 86, 2176

(33) Smith, J. D.; Cappa, C. D.; Messer, B. M.; Drisdell, W. S.; Cohen, R. C.; Saykally, R. J. J. Phys. Chem. B 2006, 110, 20038.

(34) Godbout, N.; Salahub, D. R.; Andzelm, J.; Wimmer, E. Can. J. Chem. 1992, 70, 560 .

(35) Huzinaga, S. J. Chem. Phys. 1965, 42, 1293.

(36) Näslund, L. A.; Edwards, D. C.; Wernet, P.; Bergmann, U.; Ogasawara, H.; Pettersson, L. G. M.; Myneni, S.; Nilsson, A. J. Phys. Chem. A 2005, 109, 5995.

(37) Näslund, L. A.; Cavalleri, M.; Ogasawara, H.; Nilsson, A.; Pettersson, L. G. M.; Wernet, P.; Edwards, D. C.; Sandstrom, M.; Myneni, S. J. Phys. Chem. A 2003, 107, 6869.

(38) Winter, B.; Weber, R.; Widdra, W.; Dittmar, M.; Faubel, M.; Hertel,

I. V. J. Phys. Chem. A 2004, 108, 2625.

(39) Wernet, P.; Nordlund, D.; Bergmann, U.; Cavalleri, M.; Odelius, M.; Ogasawara, H.; Naslund, L. A.; Hirsch, T. K.; Ojamae, L.; Glatzel, P.; Pettersson, L. G. M.; Nilsson, A. Science 2004, 304, 995.

(40) Cavalleri, M.; Odelius, M.; Nordlund, D.; Nilsson, A.; Pettersson, L. G. M. Phys. Chem. Chem. Phys. 2005, 7, 2854.

(41) Odelius, M.; Cavalleri, M.; Nilsson, A.; Pettersson, L. G. M. Phys. Rev. B 2006, 73.

(42) Ohtaki, H.; Radnai, T. Chem. Rev. 1993, 93, 1157.

(43) See Supporting Information.

(44) Ayotte, P.; Weddle, G. H.; Kim, J.; Johnson, M. A. J. Am. Chem. Soc. 1998, 120, 12361.

(45) Robertson, W. H.; Johnson, M. A. Annu. Rev. Phys. Chem. 2003, 54,173

(46) Kim, J.; Lee, H. M.; Suh, S. B.; Majumdar, D.; Kim, K. S. J. Chem. Phys. 2000, 113, 5259 .

(47) Lee, H. M.; Tarkeshwar, P.; Kim, K. S. J. Chem. Phys. 2004, 121, 4657.

(48) Combariza, J. E.; Kestner, N. R.; Jortner, J. J. Chem. Phys. 1994, $100,2851$.

(49) Cavalleri, M.; Ogasawara, H.; Pettersson, L. G. M.; Nilsson, A. Chem. Phys. Lett. 2002, 364, 363.

(50) Marx, D. ChemPhysChem, 2006, 7, 1848. 